\title{
Toward High-Temperature Stability of PTB7-Based Bulk Heterojunction Solar Cells: Impact of Fullerene Size and Solvent Additive
}

\author{
Sadok Ben Dkhil, Martin Pfannmöller, Maria Ilenia Saba, Meriem Gaceur, Hamed Heidari, \\ Christine Videlot-Ackermann, Olivier Margeat, Antonio Guerrero, Juan Bisquert, \\ Germa Garcia-Belmonte, Alessandro Mattoni,* Sara Bals, * and Jörg Ackermann*
}

The use of fullerene as acceptor limits the thermal stability of organic solar cells at high temperatures as their diffusion inside the donor leads to phase separation via Ostwald ripening. Here it is reported that fullerene diffusion is fully suppressed at temperatures up to $140^{\circ} \mathrm{C}$ in bulk heterojunctions based on the benzodithiophene-based polymer (the poly[[4,8-bis[(2-ethylhexyl)oxy]benzo[1,2-b:4,5-b']dithiophene-2,6-diyl][3-fluoro-2-[(2-ethylhexyl)carbonyl]thieno[3,4-b]thiophenediyl]], (PTB7) in combination with the fullerene derivative [6,6]-phenyl-C71-butyric acid methyl ester $\left(\mathrm{PC}_{70} \mathrm{BM}\right)$. The blend stability is found independently of the presence of diiodooctane (DIO) used to optimize nanostructuration and in contrast to PTB7 blends using the smaller fullerene derivative $\mathrm{PC}_{70} \mathrm{BM}$. The unprecedented thermal stability of $\mathrm{PTB7}: \mathrm{PC}_{70} \mathrm{BM}$ layers is addressed to local minima in the mixing enthalpy of the blend forming stable phases that inhibit fullerene diffusion. Importantly, although the nanoscale morphology of DIO processed blends is thermally stable, corresponding devices show strong performance losses under thermal stress. Only by the use of a high temperature annealing step removing residual DIO from the device, remarkably stable high efficiency solar cells with performance losses less than $10 \%$ after a continuous annealing at $140{ }^{\circ} \mathrm{C}$ over 3 days are obtained. These results pave the way toward high temperature stable polymer solar cells using fullerene acceptors.

\section{Introduction}

Polymer solar cells (PSCs) are among the most promising approaches toward low-cost environmentally sustainable and renewable photovoltaic devices. ${ }^{[1-3]}$ Through constant improvement in organic materials and device structure, power conversion efficiencies (PCE) of more than $10 \%$ at lab scale level and $7 \%$ at module level, respectively, could be reached, highlighting the potential of organic solar cells for applications in solar energy conversion. ${ }^{[1-7]}$ Despite these strong technological improvements, the insufficient stability is still a limiting factor for commercialization of PSCs. ${ }^{[8-12]}$ Thus one of the key challenges of PSC technology is to overcome thermal instability of organic solar cells. Industrial standards demand for high-throughput roll-to-roll processing that usually requires several heating steps at high temperature to evaporate solvents from the printed layers. As $140{ }^{\circ} \mathrm{C}$ marks the maximal temperature allowed for heat
Dr. S. B. Dkhil, Dr. M. Gaceur, Dr. C. Videlot-Ackermann,

Dr. O. Margeat, Dr. J. Ackermann

Aix Marseille Univ.

CNRS, CINaM

Marseille, France

E-mail: ackermann@cinam.univ-mrs.fr

Dr. M. Pfannmöller, Dr. H. Heidari, Prof. S. Bals

Electron Microscopy for Materials Research (EMAT)

University of Antwerp

Groenenborgerlaan 171, 2020 Antwerp, Belgium

E-mail: sara.bals@uantwerpen.be

Dr. M. I. Saba, Dr. A. Mattoni

Istituto Officina dei Materiali (CNR-IOM)

UOS Cagliari SLACS

Cittadella Universitaria

I-09042 Monserrato, Cagliari, Italy

E-mail: mattoni@iom.cnr.it
Dr. A. Guerrero, Prof. J. Bisquert,

Prof. G. Garcia-Belmonte

Institute of Advanced Materials (INAM)

Universitat Jaume I

12006 Castelló, Spain

Prof. J. Bisquert

Department of Chemistry

Faculty of Science

King Abdulaziz University

Jeddah, Saudi Arabia 
processing of most used plastic substrates, ${ }^{[8]}$ the development of materials and device structures resisting such high temperatures can be considered as a major challenge for PSC production. Thermal degradation of PSC devices is complex since performance losses can be related to degradation processes in each layer constituting the device, i.e., photoactive layer, interfacial layers (ILs), and electrodes. ${ }^{[8-12]}$ The photoactive layer is usually considered as the main parameter controlling thermal stability of the solar cells. It is typically composed of a lowbandgap polymer blended with soluble fullerene derivatives such as [6,6]-phenyl-C61-butyric acid methyl ester $\left(\mathrm{PC}_{60} \mathrm{BM}\right)$ or its larger analogue [6,6]-phenyl-C71-butyric acid methyl ester $\left(\mathrm{PC}_{70} \mathrm{BM}\right)$. The polymer blend is described as a bicontinuous interpenetrating network of nanosized polymer- and fullerene-rich phases called a bulk heterojunction (BHJ). It is obtained by kinetically controlling a nonequilibrium state at the nanoscale during solution processing. As a consequence, $\mathrm{BHJs}$ are unstable under thermal stress as heat can drive phase separation toward micrometer-sized domains, which leads to loss in photocurrent. ${ }^{[8-10,13]}$ The tendency of fullerenes to diffuse through the polymer phase resulting in the formation of large fullerene crystals via Ostwald ripening is regarded as the primary cause. Several techniques have been developed over the last decade to improve the thermal stability of polymer:fullerene blends including the use of high glass transition temperature polymers, ${ }^{[14]}$ ternary blends with compatibilizers such as block copolymers, ${ }^{[15-17]}$ amorphous fullerene derivatives, ${ }^{[18,19]}$ donor-acceptor systems with enhanced interactions, ${ }^{[20,21]}$ functionalized side chains on the polymer, ${ }^{[22]}$ thermocleavable polymers, ${ }^{[23]}$ light-induced fullerene polymerization, ${ }^{[24,25]}$ and cross-linkable materials. ${ }^{[26,27]}$ Furthermore, it was shown that mixtures of different fullerenes can improve the thermal stability of BHJs. ${ }^{[28-32]}$ Despite an intense research, known techniques to stabilize $\mathrm{BHJs}$ either reduce only partially thermal degradation or produce poor device efficiencies. So it is a primary challenge for processing of thermally stable fullerenebased high-efficiency PSCs to identify novel strategies for inhibiting fullerene diffusion inside BHJs.

Many record-efficiency PSCs achieved in the last few years have been produced with donor polymers based on benzodithiophene (BDT). ${ }^{[30-35]}$ Among BDT-based polymers, PTB7 is nowadays one of the most studied high-efficient low-bandgap donor. Numerous studies were dedicated to understand the nanoscale morphology of PBT7:fullerene blends. ${ }^{[33,34]}$ Additives such as diiodooctane (DIO) are usually used to optimize the nanoscale morphology of the blend leading to PTB7-based solar cells with efficiencies up to of $9.2 \% .{ }^{[35,36]}$ The compatibility of PTB7 with air processing at large size together with the high efficiency makes it a promising model system. ${ }^{[5,6]}$ However PTB7-based solar cells are generally known to degrade rapidly under thermal stress. It was shown that PTB7 blended with $\mathrm{PC}_{60} \mathrm{BM}$ forms thermally unstable $\mathrm{BHJ}$ s that show pronounced formation of fullerene crystals under high temperature stress of $140{ }^{\circ} \mathrm{C}$ and $150{ }^{\circ} \mathrm{C}$ due to fast Ostwald ripening. ${ }^{[25,27]}$ While thermal stability of PTB7:PC ${ }_{70} \mathrm{BM}$ blends was not yet studied in details, device using PTB7: $\mathrm{PC}_{70} \mathrm{BM}$ BHJs processed with DIO show already strong losses in performance at moderate annealing temperature of $80{ }^{\circ} \mathrm{C}-100{ }^{\circ} \mathrm{C} .{ }^{[37]}$ In contrast, solar cells using PTB7: $\mathrm{PC}_{70} \mathrm{BM}$ blends processed without DIO are reported to possess good thermal stability at $140{ }^{\circ} \mathrm{C}$ in the range of several minutes. ${ }^{[38,39]}$ Similar results were obtained for solar cells using poly[(4,8-bis-(2-ethylhexyloxy)-benzo[1,2-b;4,5b]dithiophene)-2,6-diyl-alt-(4-(2-ethyl-hexanoyl)-thieno[3,4-b]thiopene)-2,6-diyl] (PBDTTT-C): $\mathrm{PC}_{70} \mathrm{BM}$ BHJs. ${ }^{[41]}$ Yao et al. demonstrated that these devices using DIO already yield strong performance losses of $20 \%$ during short heating at $70{ }^{\circ} \mathrm{C}$, while thermal stability of devices processed without DIO was strongly increased and independent of temperature up to $100{ }^{\circ} \mathrm{C} \cdot{ }^{[40]}$ These results suggest that solvent additives such as DIO as third component of the BHJ has also to be taken into account when studying thermal stability of organic solar cells.

The focus of this work is to study the impact of the polymer blend composition on the thermal stability of high efficiency PTB7:fullerene PSCs at elevated temperature up to $140{ }^{\circ} \mathrm{C}$. We processed devices up to square-centimeter size and investigated the thermal stability of both polymer blends and complete devices as a function of fullerene size, i.e., $\mathrm{PC}_{70} \mathrm{BM}$ or $\mathrm{PC}_{60} \mathrm{BM}$, and the use of $\mathrm{DIO}$ as additive. To gain a precise description of the thermal stability of the organic solar cells, complete devices were annealed in order to take into account the contribution of each component of the solar cell to the degradation processes. Additionally, annealing at $140{ }^{\circ} \mathrm{C}$ of complete devices is technologically highly relevant as the integration of PSCs into commercial products such as buildings, vehicles, and flexible devices may demand high temperature steps for thermal lamination. Our results show that PTB7 blends using the larger fullerene derivate $\mathrm{PC}_{70} \mathrm{BM}$ form $\mathrm{BHJ}$ with excellent thermal stability, independently whether they are processed with or without DIO. Importantly these BHJs exhibit suppressed fullerene diffusion during annealing at $140{ }^{\circ} \mathrm{C}$ over $24 \mathrm{~h}$, which was revealed by means of nanoscale spectroscopic imaging making the visualization of the morphology at nanometer level possible. Understanding of this exceptional thermal stability of PTB7 blended with the larger fullerene derivate was obtained by studying the mixing enthalpy of the blend as a function of the fullerene mass ratio. In particular, molecular dynamics simulations suggest that the suppression of the fullerene diffusion inside $\mathrm{BHJ}$ s can be explained by a favorable aggregation of the $\mathrm{PC}_{70} \mathrm{BM}$ with $\mathrm{PTB} 7$ at the molecular scale. We found in fact deep local minima in the mixing enthalpy of the PTB7:PC ${ }_{70} \mathrm{BM}$ blends, which corresponds to highly stable $\mathrm{PTB} 7: \mathrm{PC}_{70} \mathrm{BM}$ aggregates able to inhibit fullerene diffusion between polymer- and fullerene-enriched phases. In contrast, for the PTB7:PC ${ }_{60} \mathrm{BM}$, this mechanism is severely reduced and insufficient to induce thermal stability. We further investigated the thermal stability of complete solar cells using PTB7:PC ${ }_{70} \mathrm{BM}$ $\mathrm{BHJ}$ s processed with and without DIO, respectively. Our results reveal that although both $\mathrm{BHJs}$ are thermally stable, the presence of residual DIO inside the polymer blend induces strong device degradation during the thermal annealing of the solar cells up to $120{ }^{\circ} \mathrm{C}$. However, removing DIO by a short high temperature annealing step at $140{ }^{\circ} \mathrm{C}$ from the device yields remarkably stable high-efficiency $\mathrm{PTB} 7: \mathrm{PC}_{70} \mathrm{BM}$-based solar cells that show losses in device performance by less than $10 \%$ after continuous annealing at $140{ }^{\circ} \mathrm{C}$ of complete devices up to 3 days. 


\section{Results and Discussion}

In the first section, we studied in detail the thermal stability, i.e., morphology changes of PTB7 polymer blends as a function of fullerene size by using either $\mathrm{PC}_{60} \mathrm{BM}$ or $\mathrm{PC}_{70} \mathrm{BM}$ as well as the use of DIO during blend processing. The chemical structures of PTB7, $\mathrm{PC}_{60} \mathrm{BM}$, and $\mathrm{PC}_{70} \mathrm{BM}$ are provided in Figure 1. In the second section, we selected the thermally stable polymer blend, i.e., PTB7:PC ${ }_{70} \mathrm{BM}$, to process solar cells and studied the performance of the corresponding devices under thermal stress as a function of annealing temperatures.

\subsection{Thermal Stability of PTB7 Blends}

The thermal stability of the polymer blends was first studied at the microscale using optical microscopy. Figure 1 compares images from optical microscopy of PTB7:PC ${ }_{60} \mathrm{BM}$ and PTB7:PC ${ }_{70} \mathrm{BM}$ blend layers processed with DIO under different thermal annealing conditions. The blends were first dried under high vacuum during $12 \mathrm{~h}$ in order to remove DIO in accordance to literature. ${ }^{[5,41]}$ The vacuum dried as-casted films are uniform without visible microscale features. The dark spots observed here are related to defects in the camera of the microscope. After $1 \mathrm{~h}$ of annealing at $140^{\circ} \mathrm{C}$, the PTB7:PC ${ }_{60} \mathrm{BM}$ films show the formation of fullerene crystals that increase in size and number after further annealing for $1 \mathrm{~d}$. This observation is in agreement with recent works on PTB7 blends. ${ }^{[25,27]}$ In contrast, PTB7:PC $\mathrm{P}_{70} \mathrm{BM}$ blends do not show any fullerene crystals visible by optical microscopy after one day thermal annealing at $140{ }^{\circ} \mathrm{C}$. Importantly, the remarkable thermal stability of the PTB7:PC ${ }_{70} \mathrm{BM}$ blends was found to be independent of $\mathrm{PC}_{70} \mathrm{BM}$ purity (95\% and 99\%) and PTB7 batches. This clearly shows that there is a strong improvement in thermal stability of PTB7 polymer blends using the larger fullerene derivative $\mathrm{PC}_{70} \mathrm{BM}$. As shown in Figure S1 (Supporting Information), the increase in annealing temperature to $200{ }^{\circ} \mathrm{C}$ leads to the formation of fullerene crystals in both cases already after $1 \mathrm{~h}$ indicating that PTB7:PC ${ }_{70} \mathrm{BM}$ still behaves like a classical polymer blend with Ostwald ripening at temperature as high as $200{ }^{\circ} \mathrm{C}$. We also investigated PTB7 blends processed without DIO under identical thermal stress. As shown in Figure 1 after annealing at $140{ }^{\circ} \mathrm{C}$ for one day PTB7: $\mathrm{PC}_{60} \mathrm{BM}$ films show still the formation of large fullerene crystals, while PTB7: $\mathrm{PC}_{70} \mathrm{BM}$ films appear stable at this scale. This implies that the difference in thermal stability observed as a function of fullerene size is independent of DIO. We further questioned whether PTB7:PC ${ }_{60} \mathrm{BM}$ films resist thermal annealing at lower temperature. As shown in Figure S2 (Supporting Information), fullerene crystal formation can be still observed even if the temperature is reduced to $100{ }^{\circ} \mathrm{C}$. Thus, there is a large difference in thermal stability of the PBT7 blends depending on the fullerene size.

As optical images only give information about thermal stability of PTB7:PC ${ }_{70} \mathrm{BM}$ at macroscopic level, it is still possible that there are changes at the nanoscale induced by the $140{ }^{\circ} \mathrm{C}$ annealing. Therefore, we applied scanning transmission electron microscopy combined with spatially resolved spectroscopic imaging (STEM-SI) of the low-energy loss to distinguish between donor and acceptor phases of the polymer blend down to nanoscale level. First, we present results of DIO processed as-casted blend layers. Figure 2 a shows an annular dark-field STEM micrograph of as-casted blend layers. In general, conventional imaging modes in TEM or STEM do not provide sufficient contrast due to low variations in density and elemental composition. ${ }^{[42]}$ Instead, differences in optical excitation spectra can be correlated to $\mathrm{PC}_{70} \mathrm{BM}$ - and PTB7-enriched domains. Thereby, peaks are fitted by Lorentzian model functions to determine the center position. ${ }^{[43]}$ The plasmon peak map for the as-casted blend in Figure $2 \mathrm{~b}$ reveals that very small to medium-sized $(3-50 \mathrm{~nm})$ fullerene-enriched domains are present in blends processed with DIO. Using spatially resolved low-energy-loss spectra, a segmentation of the domains into

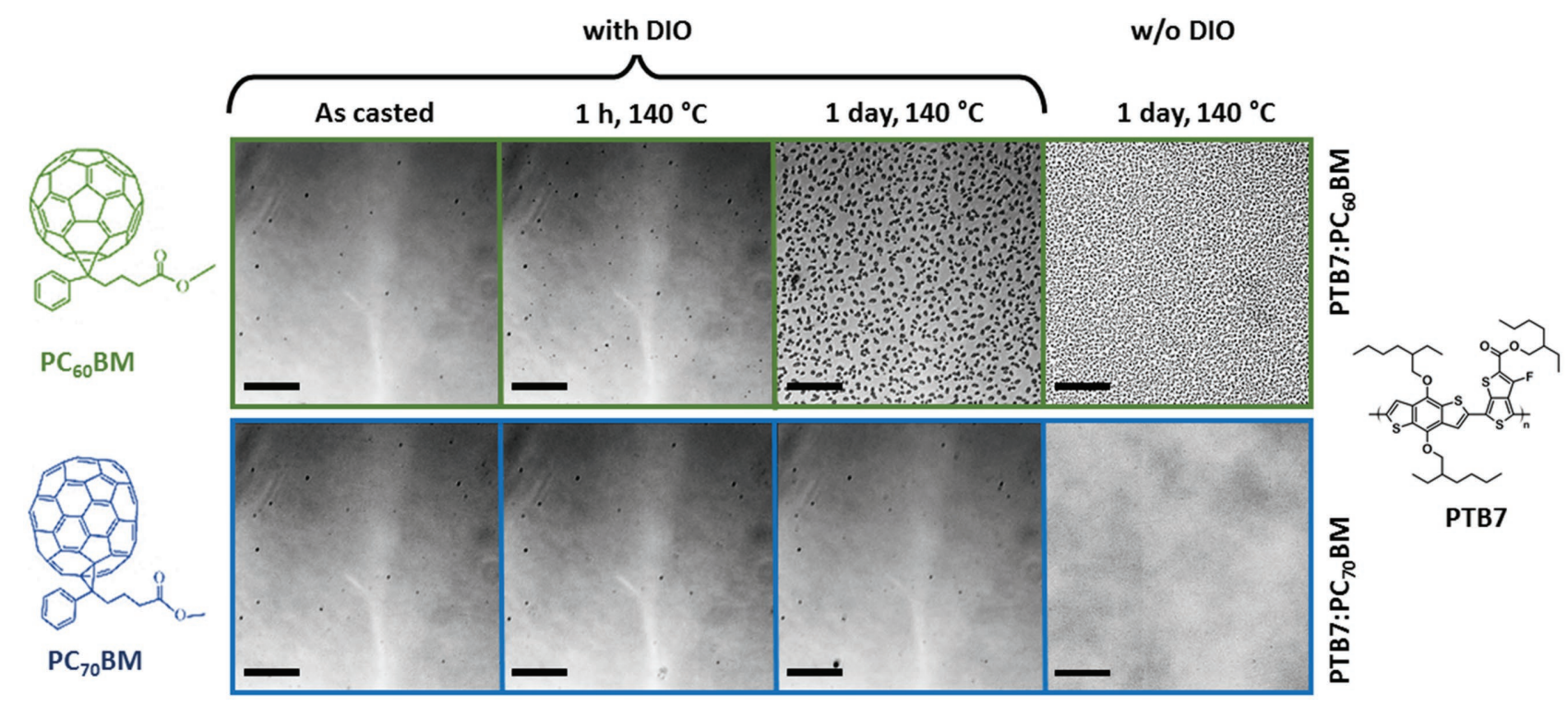

Figure 1. Optical images of PTB7:PC ${ }_{60} \mathrm{BM}$ and PTB7:PC ${ }_{70} \mathrm{BM}$ blends with and without DIO deposited onto ITO/PEDOT:PSS substrates and exposed to different thermal annealing steps (time, temperature); scale bar correspond to $50 \mu \mathrm{m}$. Chemical structures of $\mathrm{PTB} 7, \mathrm{PC}_{60} \mathrm{BM}$, and $\mathrm{PC} \mathrm{C}_{70} \mathrm{BM}$ are $\mathrm{provided}$. 

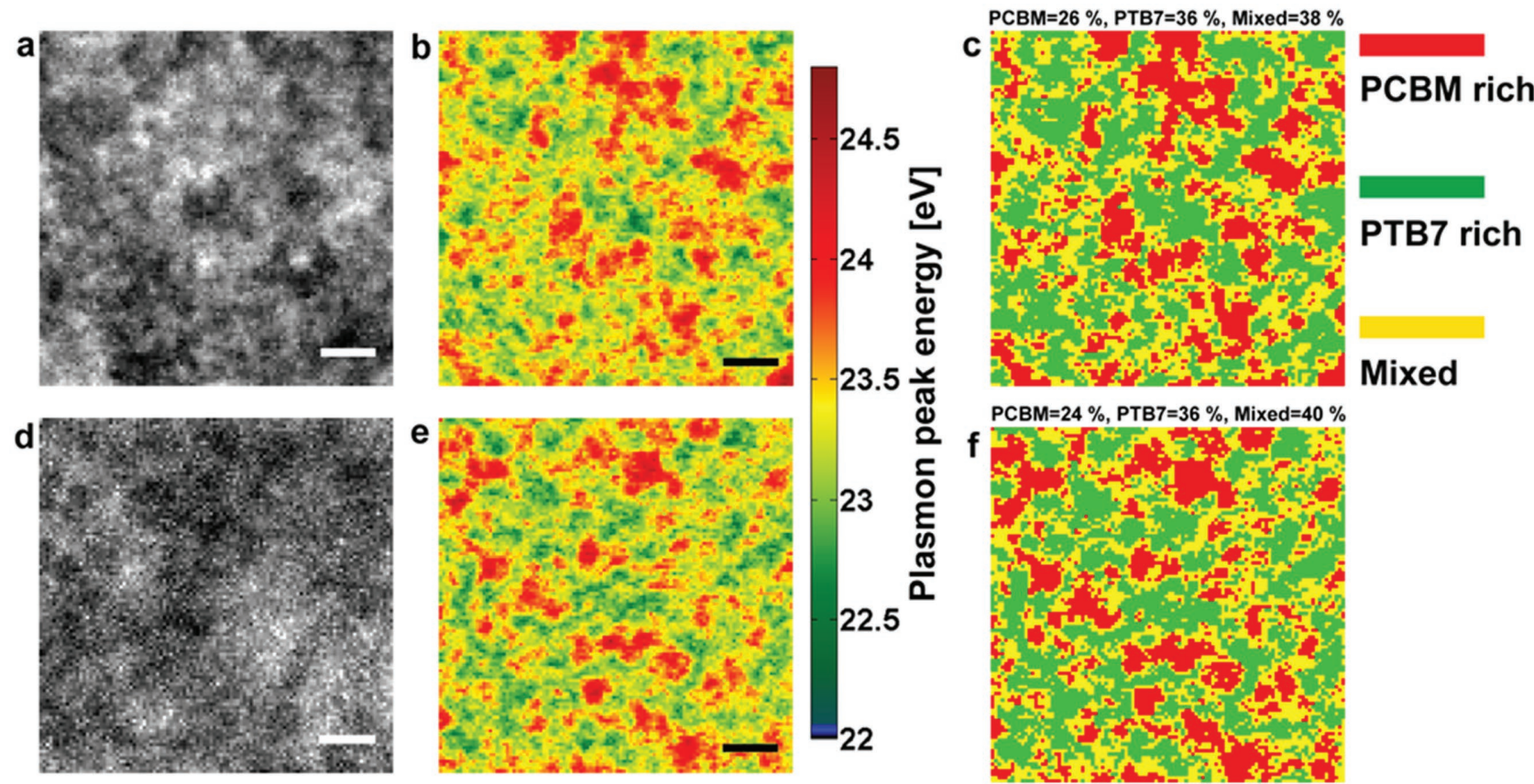

Figure 2. Lateral view analysis of PTB7:PC $\mathrm{PC}_{70} \mathrm{BM}$ blends processed with DIO: a) Conventional annular dark-field STEM micrograph of the as-casted photoactive layer, b) plasmon peak map of the same area of observation showing the nanoscale materials phases $\left(\mathrm{PC}_{70} \mathrm{BM}\right.$ rich in red with high plasmon peak energy and PTB7 rich in green with low energy), and c) segmentation of the same area into enriched and mixed domains. $d-f$ ) Same image information and analysis for the film annealed for $1 \mathrm{~d}$ at $140{ }^{\circ} \mathrm{C}$. (Scale bars $50 \mathrm{~nm}$ ).

different material classes was carried out, enabling also identification of enriched and mixed phases. The spectral segmentation was performed as previously applied for P3HT:PC ${ }_{60} \mathrm{BM}$ blends. ${ }^{[44]}$ It yields the distribution of enriched (red and green colors in Figure 2) but also of the mixed phases (yellow color in Figure 2). Plasmon peak energies for mixed areas are $23.35 \mathrm{eV}$, which is approximately the center between the minimum and maximum presented in the map in Figure $2 \mathrm{~b}$. This implies that areas segmented as mixed phase will show a molecular $\mathrm{PC}_{70} \mathrm{BM}$ composition of around $45 \%$, i.e., $\approx 52 \mathrm{wt} \%$ taking into account the higher molecular mass in comparison to the molecular mass of PTB7 monomers. As seen in Figure 2c, as-casted blends consist of $\approx 26 \%$ domains of $\mathrm{PC}_{70} \mathrm{BM}$ enrichment, $36 \%$ of PTB7 enrichment, and a high fraction (38\%) of mixed phases. We estimated the fullerene concentration of the PTB7 enriched domains to be of $27 \%$ as determined by STEM-SI analysis of $\mathrm{PTB} 7: \mathrm{PC}_{70} \mathrm{BM}$ layer processed without DIO (see Figure S3, Supporting Information). Indeed as such layers consist of large fullerene clusters embedded in polymer-enriched domains, it is therefore possible to estimate the fullerene concentration inside the polymer-enriched phase. This value corresponds to the maximum miscibility of $\mathrm{PC}_{70} \mathrm{BM}$ in PTB7 as reported in the literature. ${ }^{[33]}$ Figure 2d-f shows the STEM-SI analysis of the PTB7:PC ${ }_{70} \mathrm{BM}$ blend processed with DIO annealed for $24 \mathrm{~h}$ at $140{ }^{\circ} \mathrm{C}$. Importantly, very similar domain sizes and material compositions were found. To gain a deeper insight into potential morphological changes under thermal stress, we performed more STEM-SI analysis at three different sample positions of ascasted and annealed blend layers as shown in Figure S4 and S5 (Supporting Information). Importantly, the results reveal that the ratio of the three material phases is quasi-identical after the high-temperature annealing over $24 \mathrm{~h}$ as given in Table S1 (Supporting Information). Furthermore, we still observe a large amount of very small fullerene enriched clusters $(<10 \mathrm{~nm}$ in diameter) despite the long and high-temperature annealing. This finding indicates that the Ostwald-ripening mechanism is suppressed inside the PTB7:PC ${ }_{70} \mathrm{BM}$ blend at $140{ }^{\circ} \mathrm{C}$. Identical behavior is found for $\mathrm{PTB} 7: \mathrm{PC}_{70} \mathrm{BM}$ blends processed without DIO as shown in Figure S6 (Supporting Information). In contrast, the PTB7:PC $\mathrm{P}_{70} \mathrm{BM}$ blend nanoscale morphology after annealing at $200{ }^{\circ} \mathrm{C}$ for $1 \mathrm{~h}$ is dramatically altered with $500 \mathrm{~nm}$ sized fullerene domains and disappearance of small nanometer-sized fullerene clusters as shown in Figure S7 (Supporting Information). This is in accordance with the appearance of large fullerene crystals in Figure S1 (Supporting Information) indicating a classical behavior of phase segregation via Ostwald ripening at $200{ }^{\circ} \mathrm{C}$.

In order to understand the difference in thermal stability of polymer blends processed with $\mathrm{PC}_{60} \mathrm{BM}$ and $\mathrm{PC}_{70} \mathrm{BM}$, respectively, and especially the lack of fullerene diffusion in PTB7:PC ${ }_{70} \mathrm{BM}$ blends, we consider first the possibility that specific PTB7 structures play a role in the mechanism. Indeed, it was proposed recently that fullerene diffusion is reduced in PTB7:PC ${ }_{70} \mathrm{BM}$ blends by formation of fibrillar PTB7 networks inside the blend. ${ }^{[33]}$ Polymer blends based on different batches of PTB7 combined with $\mathrm{PC}_{70} \mathrm{BM}$ of $95 \%$ purity were analyzed. Indeed we also observed such fibrillar structures, but only in few PTB7:PC 70 BM samples, while most layers were found free of such structures. Figure S8 (Supporting Information) shows TEM images of such fibrillar networks, together with the STEM-SI analysis of the same blend. The morphological map of the STEM-SI analysis only shows a PTB7:PC ${ }_{70} B M$ 
morphology similar to those shown in Figure 2 and not a fibrillar structure. This demonstrates that these networks are not composed of PTB7, but are rather related to impurities in some PTB7 batches. Furthermore, as BHJs were thermally stable at $140{ }^{\circ} \mathrm{C}$ for all studied PTB7 batches, our analyses clearly prove that fibrillar networks are not at the origin of the suppression of fullerene diffusion. Another parameter controlling fullerene diffusion is the glass transition temperature $T_{\mathrm{g}}{ }^{\text {blend }}$ of the blends. ${ }^{[45]}$ Indeed annealing the $\mathrm{BHJ}$ above $T_{\mathrm{g}}$ blend is considered to cause rapid formation of fullerene crystals being detrimental for device performance. ${ }^{[8-10,13]}$ Typically, glass transition behavior is studied by differential scanning calorimetry (DSC), ${ }^{[46]}$ but paracrystalline polymers such as PTB7 do not show a $T_{\mathrm{g}} \cdot{ }^{[47,48]} \mathrm{DSC}$ analysis of PTB7:PC ${ }_{70} \mathrm{BM}$ do not show phase transition up to $200{ }^{\circ} \mathrm{C}$ making it difficult to understand their thermal stability as demonstrated recently. ${ }^{[47]}$ Furthermore, $T_{\mathrm{g}}$ depends on several factors such as thermal history of the sample, technique and thermal rate used for the measurement, ${ }^{[49]}$ thickness of the layers and substrate nature, ${ }^{[50]}$ aggravating the understanding of the thermal stability of PTB7-based polymer blends via DSC. Liu et al. studied bilayers of $\mathrm{PC}_{70} \mathrm{BM}$ and PTB7 that were thermally annealed at $150{ }^{\circ} \mathrm{C} .{ }^{[33]}$ They found that diffusion of fullerene into the PTB7 occurs until the thermodynamic limit of $\mathrm{PC}_{70} \mathrm{BM}$ solubility in PTB7 is reached.

Taking these results into account, we investigated the intrinsic thermodynamic stability of the PTB7 blends using the two fullerene derivatives $\mathrm{PC}_{60} \mathrm{BM}$ and $\mathrm{PC}_{70} \mathrm{BM}$. For this purpose molecular dynamics simulations were adopted to estimate the enthalpy of mixing of the polymer:fullerene blends. ${ }^{[51]}$ As thermal stability was found independently of DIO, the solvent additive was not considered in the simulations. The enthalpy of mixing is a key thermodynamic parameter to measure the stability of a blend and it is defined as the energy gain per unit volume of mixture with respect to the two separate components, ${ }^{[52]} \Delta H / V_{\mathrm{m}}=\left(E_{\mathrm{m}}-E_{\mathrm{A}}-E_{\mathrm{B}}\right) / V_{\mathrm{m}}$ where $V_{\mathrm{m}}$ and $E_{\mathrm{m}}$ are the energy and the volume of the mixture, and $E_{\mathrm{A}}$ and $E_{\mathrm{B}}$ are the energies of the separated PTB7 and fullerene phases. According to the Flory-Huggins theory, ${ }^{[52]}$ the free energy mixing includes also the configurational entropy (see Supporting Information) that is a known function of the concentration; however, this contribution is practically identical for the two blends so that the stability mainly depends on the enthalpy (further details can be found in Supporting Information) that can be calculated by molecular dynamics. To this aim it is first necessary to build the corresponding crystalline bulks for polymers and fullerenes and calculate the corresponding cohesive energies densities (CED) at equilibrium volumes. We found $241 \mathrm{MPa}$ for the PTB7 polymer and 432 and $391 \mathrm{MPa}$ for $\mathrm{PC}_{60} \mathrm{BM}$ and $\mathrm{PC}_{70} \mathrm{BM}$, respectively. These values are in good agreement with experimental data from literature. ${ }^{[53]}$ In order to study the enthalpy of mixing at different concentrations and to explore the possible morphologies of the blends, we generated $\approx 100$ systems formed by PTB7 and $\mathrm{PC}_{60} \mathrm{BM}$ (or $\mathrm{PC}_{70} \mathrm{BM}$ ) molecules, with varying numbers of fullerenes and varying initial dispositions within the polymer. The systems were carefully equilibrated by $10 \mathrm{~ns}$ long constant pressure and constant temperature annealing (NPT) at room conditions, during which anisotropic volume fluctuations were allowed. In fact, polymer systems are known to have a complex configurational landscape that requires full relaxation and a suitable sampling of the configurational space. ${ }^{[51,54]}$ Examples of molecular distribution inside the polymer blend at three different fullerene concentrations (i.e., mass ratios) are reported in Figure 3a. A rich statistics of configurations was obtained in this way enabling calculation of the energy as a function of the fullerene concentration (see additional details in the Supporting Information). The whole range of concentrations has been explored including $0 \%$ and $100 \%$ at which the mixing enthalpy is zero by definition. Since there is generally a demand of energy to form the blend, the lower $\Delta H / V$ indicates more stable systems. ${ }^{[52]}$ As shown in Figure $3 \mathrm{~b}$ we find that $\mathrm{PTB} 7: \mathrm{PC}_{70} \mathrm{BM}$ blends have generally lower mixing enthalpy than PTB7: $\mathrm{PC}_{60} \mathrm{BM}$, which is in accordance with the higher thermal stability of the blend shown experimentally in Figure 1 . This result can be attributed to the higher binding energy between the single $\mathrm{PC}_{70} \mathrm{BM}$ molecule and the PTB7 backbone $(\approx 2.1 \mathrm{eV}$ per fullerene for $\mathrm{PC}_{70} \mathrm{BM}$ versus $1.8 \mathrm{eV}$ for $\left.\mathrm{PC}_{60} \mathrm{BM}\right)$, to the higher cohesive energy of the $\mathrm{PC}_{70} \mathrm{BM}$, and a better $\mathrm{PC}_{70} \mathrm{BM}$ organization with respect to the polymer backbone compared to $\mathrm{PC}_{60} \mathrm{BM}$. Indeed, calculations suggest that the chains of PTB7 are better aligned in combination with $\mathrm{PC}_{70} \mathrm{BM}$, probably due to an improved matching between the larger fullerene and the polymer units. This reduces the amount of polymer strain and thus the energy of mixing. More importantly, our calculations further show the existence of two local minima in the cohesive energy curves for both fullerenes. While the minima for PTB7:PC ${ }_{60} \mathrm{BM}$ are not pronounced and have still high enthalpy values (see Figure $3 \mathrm{~b}$ ), $50 \%$ of $\mathrm{PC}_{70} \mathrm{BM}$ content generates a deep minimum of $\Delta H / V$ indicating a highly stable phase in which the blend and the separate phases have similar enthalpy values and thus no driving force for phase separation exists. The low mixing enthalpy derives from the high fullerene/PTB7 interaction that leads to densely packed regions of fullerene molecules intercalated within the polymer. Figure 3a shows the corresponding fullerene organization inside the PTB7 blend using 50\% of $\mathrm{PC}_{70} \mathrm{BM}$ content. The first minimum of $\Delta H / V$ observed at $25 \%$ (middle panel) corresponds qualitatively to a similar fullerene aggregation as in the high concentration regime (50\%) but occurring only in separate regions of the polymer matrix as visualized in Figure $3 \mathrm{a}$. In the case of $50 \%$ content, the fullerenes occupy the whole polymer system, which results in an optimal polymer alignment, a decrease of enthalpy and thus improvement in stability. These results are in line with the STEM-SI analysis presented in Figure 2c,f, which show that the most frequently observed and thus most stable phase inside the PTB7:PC ${ }_{70} \mathrm{BM}$ blends corresponds to the mixed phase with an average fullerene concentration of $\approx 50 \%$. Based on these results, we suggest that the densely intercalated polymer:fullerene (DIP) phases formed at $25 \%$ and $50 \%$, respectively, may thermally stabilize the $\mathrm{PTB} 7: \mathrm{PC}_{70} \mathrm{BM}$ blend at $140{ }^{\circ} \mathrm{C}$. Indeed changing the fullerene concentration inside these DIP phases will induce strain on the polymer that costs additional energy in the $\Delta H / V$ function. ${ }^{[55,56]}$ As DIP phases always enclose fullerene-enriched phase inside the BHJ, they may thus act as barrier for fullerene diffusion and suppress phase separation via Ostwald ripening.

The calculated mixing enthalpy can be used to estimate qualitatively the relative thermal stability of the PTB7:PC ${ }_{70} \mathrm{BM}$ and PTB7: $\mathrm{PC}_{60} \mathrm{BM}$ blends. At $50 \%$ fullerene concentration, 
a

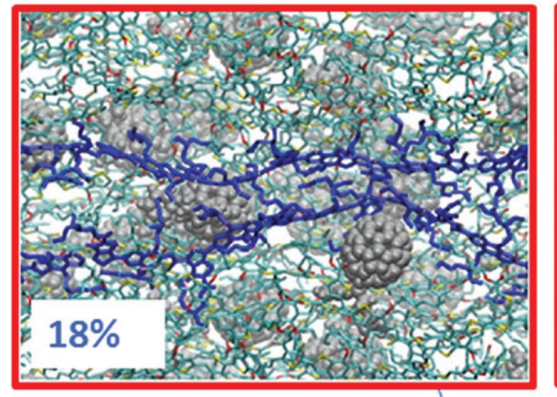

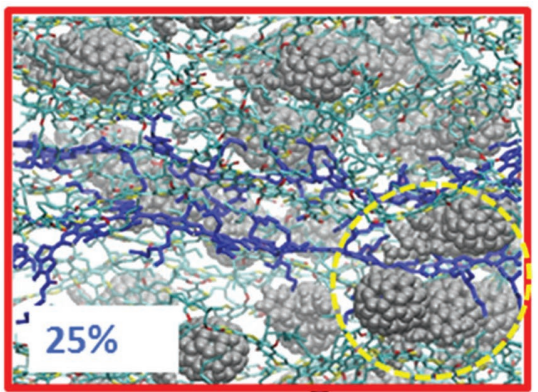

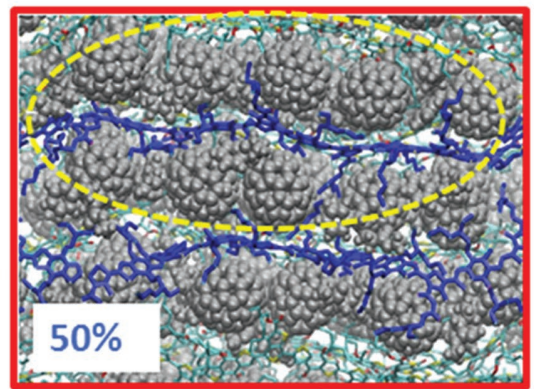

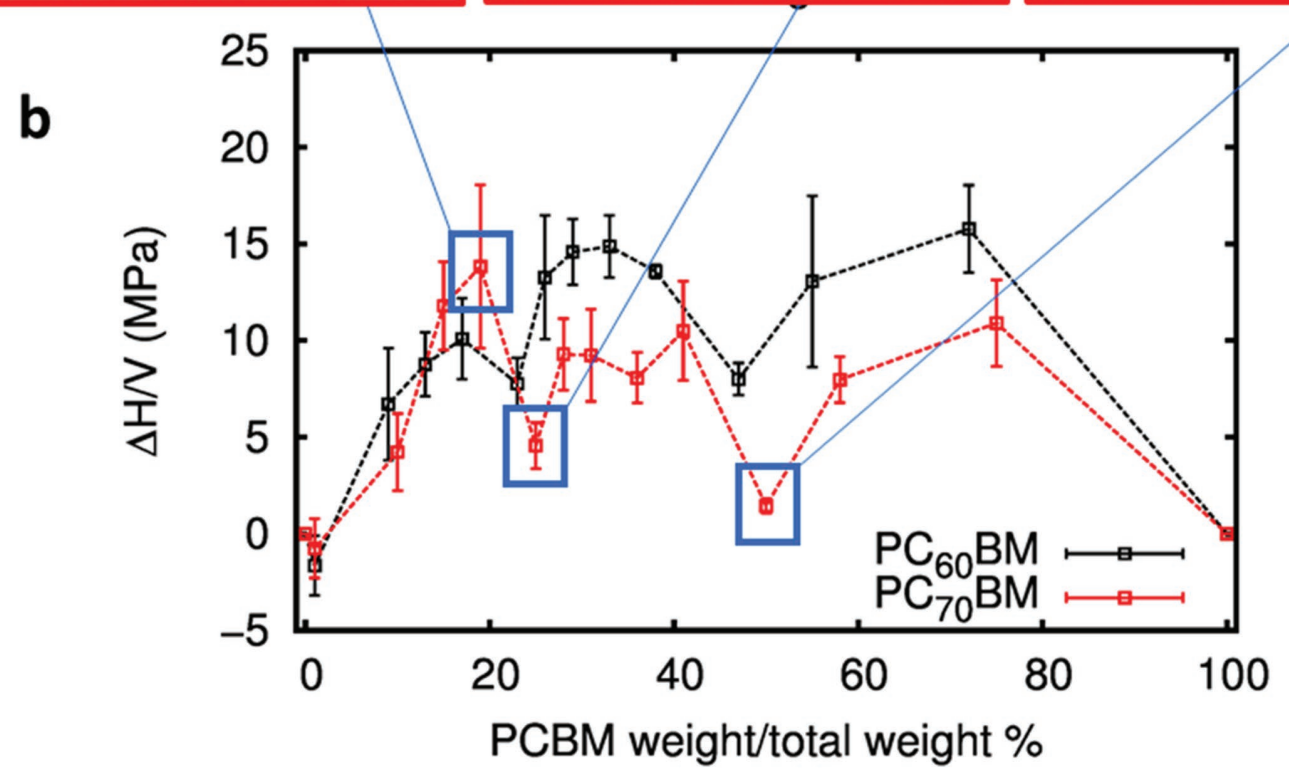

Figure 3. a) Calculated PTB7:PC $70 \mathrm{BM}$ blend morphology and b) mixing energy as a function of fullerene $\left(\mathrm{PC}_{60} \mathrm{BM}\right.$ or $\left.\mathrm{PC} 70 \mathrm{BM}\right)$ wt\% inside the polymer blend.

the $\mathrm{PC}_{70} \mathrm{BM}$ blend is more stable than $\mathrm{PC}_{60} \mathrm{BM}$ with a difference $D \approx 10 \mathrm{MPa}$. In the spirit of the Flory-Huggins theory, ${ }^{[52]}$ it can be defined a corresponding temperature difference $\Delta T=D V_{0} /\left(z k_{\mathrm{B}}\right)$, where $V_{0} \approx 1 \mathrm{~nm}^{3}$ is the fullerene volume and $z$ is the number of effective polymer-fullerene molecular interactions. By using $z \approx 12$ (i.e., the coordination number of a hexagonal close packed crystal) it is predicted $\Delta T \approx 60 \mathrm{~K}$. This value suggests that the difference in thermal stability between both blend is in the range of several tenths of ${ }^{\circ} \mathrm{C}$. This estimation is in accordance with our experiments showing the PTB7: $\mathrm{PC}_{60} \mathrm{BM}$ blends are not stable at high temperatures between $100{ }^{\circ} \mathrm{C}$ and $140{ }^{\circ} \mathrm{C}$, although PTB7:PC ${ }_{70} \mathrm{BM}$ is stable at $140{ }^{\circ} \mathrm{C}$.

\subsection{Thermal Stability of PTB7:PC 70 BM-Based Solar Cells}

After the demonstration of the thermal stability of PTB7: $\mathrm{PC}_{70} \mathrm{BM}$ layers at $140{ }^{\circ} \mathrm{C}$, we focus in this part on thermal behavior of complete solar cells using PTB7:PC ${ }_{70} \mathrm{BM}$ processed with or without DIO as active layer. The insert in Figure 4a shows the device structure in which poly(3,4-ethylenedioxythiophene) polystyrene sulfonate (PEDOT:PSS) and $\mathrm{ZnO}$ nanoparticle layers are used as hole and electron extraction layer, respectively, leading to high efficiency solar cells. ${ }^{[57]}$ The completed solar cells were exposed to post-annealing at temperatures from $80{ }^{\circ} \mathrm{C}$ to $160{ }^{\circ} \mathrm{C}$ during $1 \mathrm{~h}$ to study their thermal degradation. Figure $4 \mathrm{~b}$ depict the evolution of the $J-V$ curves of the devices under thermal stress, while Table S2 (Supporting Information) sums up the corresponding photovoltaic parameters. DIO-free solar cells show an average efficiency of $3.3 \%$ without changes in performance for temperatures up to $140{ }^{\circ} \mathrm{C}$. A clear degradation is only observed for thermal stress of $160{ }^{\circ} \mathrm{C}$. Devices processed with DIO show an average efficiency of $7.4 \%$ for nonannealed layers similar to results in our former work. ${ }^{[57]}$ However, although the blend morphology is stable up to $140{ }^{\circ} \mathrm{C}$, we observed strong losses in device performance of up to $40 \%$ for post-annealing from $80{ }^{\circ} \mathrm{C}$ to $120^{\circ} \mathrm{C}$. These losses are in line with reports in literature ${ }^{[38,39]}$ and are mainly related to strong drops in short-circuit density $\left(J_{\mathrm{sc}}\right)$ and fill factor $(\mathrm{FF})$, while the open-circuit voltage $\left(V_{\mathrm{oc}}\right)$ stays constant. In contrast, the device behavior is different for devices exposed to $140{ }^{\circ} \mathrm{C}$. In this case, the thermal treatment induces an increase in $V_{\text {oc }}$ by typically $40 \mathrm{mV}$ as well as a small increase in $J_{\mathrm{sc}}$ accompanied by a drop in FF from $65 \%$ to $58 \%$ leading to an almost unaltered efficiency of $7.2 \%$. Even continuous annealing of the devices for $3 \mathrm{~d}$ at $140{ }^{\circ} \mathrm{C}$ did not significantly reduced the efficiency (PCE reduction $<10 \%$ ) as shown in Figure 4c (black square) and Table S3 (Supporting Information). Only further increase in annealing temperature to $160{ }^{\circ} \mathrm{C}$ commenced to degrade the solar cells. This behavior is identical 

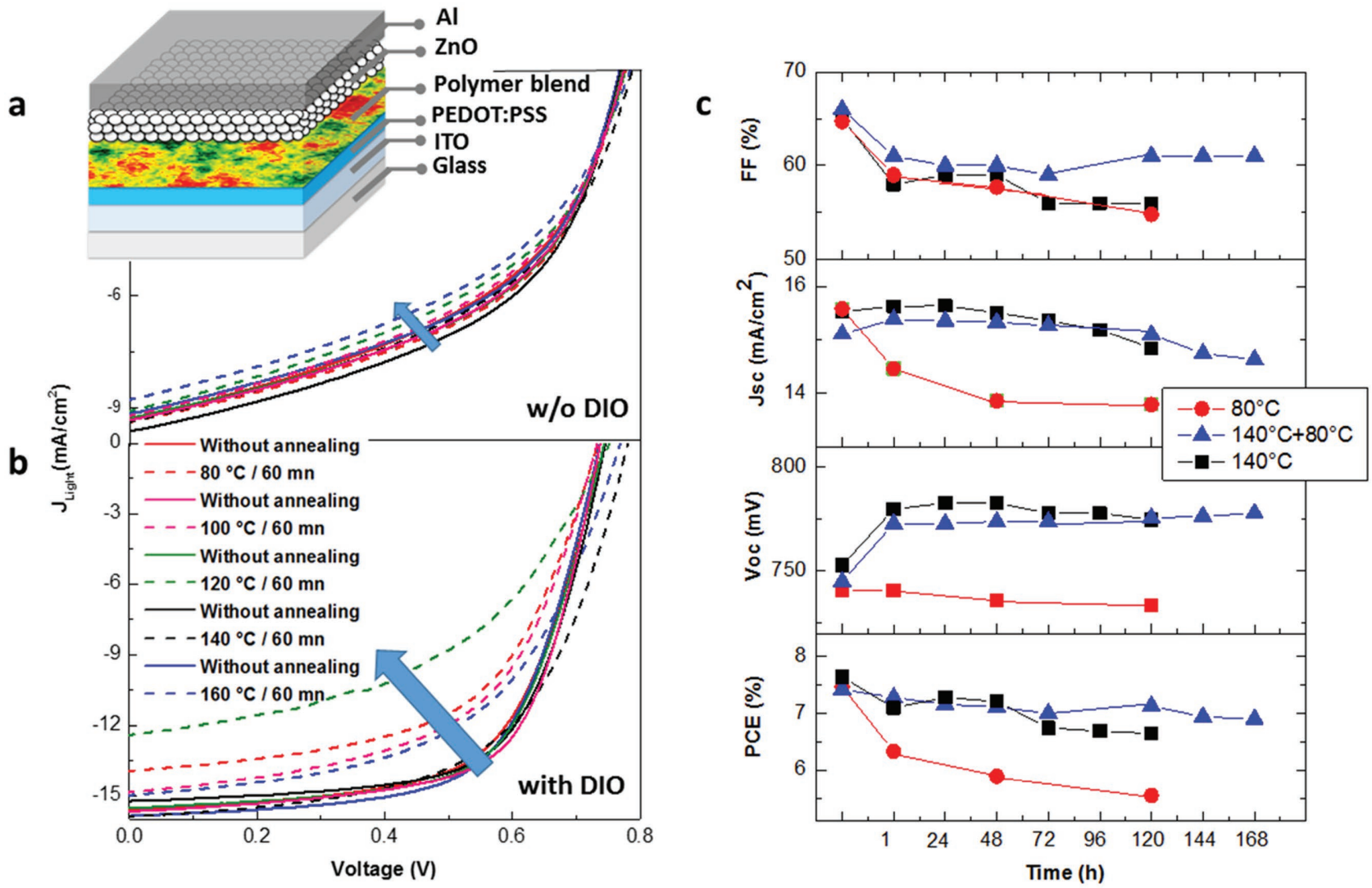

Figure 4. a) Device structure of the polymer solar cells. b) $J-V$ curves of PTB7:PC ${ }_{70} B M$ solar cells, processed without DIO and with DIO, and exposed individually to a single post-annealing step during $1 \mathrm{~h}$ with temperatures ranging from $80^{\circ} \mathrm{C}$ to $160^{\circ} \mathrm{C}$. C) Photovoltaic parameters (FF, $J_{s c}, V_{o c}$, and PCE) of PTB7:PC ${ }_{70} B M$ devices annealed continuously at $80^{\circ} \mathrm{C}$ as a function of time for solar cells prepared without (red circles) and with an initial 15 min thermal annealing step of $140{ }^{\circ} \mathrm{C}$ (blue triangles); black squares show data of PTB7: $\mathrm{PC}_{70} \mathrm{BM}$ devices annealed continuously at $140{ }^{\circ} \mathrm{C}$ during $3 \mathrm{~d}$ using $\mathrm{PC}_{70} \mathrm{BM}$ of $95 \%$ purity.

to the degradation of solar cells containing blends processed without DIO. Importantly, the device stability at $140{ }^{\circ} \mathrm{C}$ was found independently of PTB7 batches and fullerene purity and observed in a total number of more than 100 solar cells. We further processed high-efficiency $1 \mathrm{~cm}^{2}$-sized solar cells as shown in Figure S9 and Table S4 (Supporting Information). We found identical thermal stability demonstrating the ability to upscale the discovered property of PTB7: $\mathrm{PC}_{70} \mathrm{BM}$-based devices at large area. Thus, applying the post-annealing step at $140{ }^{\circ} \mathrm{C}$, which is referred as PAS-140 in the following, leads to a unprecedented gain in thermal stability and a strong increase in $V_{\mathrm{oc}}$. Taking into account that DIO-free devices were found to be thermally stable at all temperatures up to $120^{\circ} \mathrm{C}$, we suppose that DIO still present inside the solar cells causes device degradation for annealing at moderate temperatures from $80^{\circ} \mathrm{C}$ to $120^{\circ} \mathrm{C}$. It is important to mention that we apply a vacuum drying step to all polymer blends during device processing that is usually considered to remove the additives such as DIO from the blend. In order to validate the need of PAS-140 to fully remove DIO, we first treated DIO processed solar cells for 15 min with a PAS140 and measured the long-term stability of the device under permanent annealing at $80^{\circ} \mathrm{C}$. As it is highlighted in Figure $4 \mathrm{c}$ and Table S3 (Supporting Information), PAS-140 treated devices were stable over $7 \mathrm{~d}$ at $80{ }^{\circ} \mathrm{C}$ (PCE reduction $<4 \%$ ), while the device without a PAS-140 step shows losses in performance of $20 \%$ already after $1 \mathrm{~h}$. We further verified the presence of DIO inside the blend by using electron energy-loss (EELS) analysis of vacuum dried as-casted and PAS-140-treated films. The EELS analysis of the iodine signal that can be directly addressed to DIO is shown in Figure S10 (Supporting Information) indicating that indeed DIO is present inside the blend before annealing, while PAS-140 treated layers do not show any signal. Taking into account the sensitivity of EELS analysis in carbonaceous matrices, ${ }^{[58,59]}$ we estimate the reduction in DIO down to a maximum mass fraction of $\approx 1 \%$ inside the blend layer. EEL spectra from both samples were acquired after $\approx 1 \mathrm{~h}$ in the high vacuum of the microscope to prevent potentially uncontrolled evaporation of DIO. We can thus conclude that the residual DIO is responsible for thermally induced degradation of device performance at temperatures below $140{ }^{\circ} \mathrm{C}$, while a high temperature treatment such as PAS-140 allows establishing a long-term stability up to $140{ }^{\circ} \mathrm{C}$ directly related to the intrinsic thermal stability of the $\mathrm{BHJ}$ itself.

It is worth to emphasis that the thermal stability of PTB7:PC ${ }_{70} \mathrm{BM}$-based solar cells during thermal annealing at $140{ }^{\circ} \mathrm{C}$ over days implies that ILs and the interfaces between these layers and the BHJs are electronically stable during this thermal stress. It is known that thermal annealing can lead to 
diffusion of metal ion of the electrode into the organic layer creating substantial leakage current. ${ }^{[17,18]}$ Furthermore, chemical reactions at the metal/organic interface can alter the contact properties, forming interfacial dipole barriers and defect states that pin the Fermi level. ${ }^{[20,21]}$ It is therefore likely that the stability of the devices largely benefits from the use of $\mathrm{ZnO}$ buffer layers that protect the polymer blend against thermally induced damages.

In order to understand the changes in the photovoltaic parameters observed during PAS-140, i.e., increase in $V_{\text {oc }}$ and decrease in FF, we applied STEM-SI to visualize vertical changes in morphology upon annealing. First, lamellar crosssections of DIO processed samples without and with annealing at $140{ }^{\circ} \mathrm{C}$ for $1 \mathrm{~h}$ and $1 \mathrm{~d}$ were prepared by focused ion-beam milling. STEM-SI measurements as shown in Figure $5 \mathrm{a}-\mathrm{d}$ performed on these cross-sections show that after thermal annealing only a weak vertical segregation is present leading to $\mathrm{PC}_{70} \mathrm{BM}$ enrichment near the cathode region, i.e., at the interface with the $\mathrm{ZnO}$ buffer layer. We suggest that the fullerene accumulation at the blend surface is related to the evaporation of DIO during the PAS-140 step. Since DIO has a high affinity to fullerenes, it is likely that the evaporation of DIO toward the device surface is responsible for fullerene diffusion toward the blend surface. As next step, we applied impedance spectroscopy as efficient tool to study electronic changes of PSC under thermal stress. ${ }^{[37]}$ Interfaces between the active layer and outer contacts also play a very important role in device operation and stability as shown recently. ${ }^{[37,57,60]}$ The quality of an interface is influenced by potential charge accumulation and formation of leakage current, which depends on the concentration of donor and acceptor at the contacts. ${ }^{\left[{ }^{[62]}\right.}$ Here, we observe that leakage current is reduced after PAS-140 accompanied by an increase in $V_{\text {oc }}$. These electronic modifications were studied in details with impedance spectroscopy. ${ }^{[63]}$ Full impedance analysis and capacitance voltage are discussed in the Supporting Information in details, while only most relevant results are discussed here. For both annealed and nonannealed samples, we find that charge carrier extraction is highly efficient since the impedance spectroscopy measurements mainly show the recombination arc. However for the nonannealed devices (devices without PAS-140), an additional feature is observed in the low frequency region below $150 \mathrm{kHz}$, which suggests an accumulation of charges due to less efficient carrier extraction in comparison to the annealed sample (Figure S11a, Supporting Information). This result is in agreement with the light-induced dipole observed by the Mott-Schottky analysis (Figure S11b, Supporting Information) where dipole generation is manifested as a shift of $150 \mathrm{mV}$ of the linear region close to $V_{\text {oc }}$. Overall, all of these results indicate that fullerenes diffuse to the $\mathrm{ZnO}$ interfaces during thermal annealing leading to the observed increase in $V_{\text {oc}}$.

\section{Conclusion}

High-efficiency PSCs have been demonstrated that withstand temperatures of $140{ }^{\circ} \mathrm{C}$ for several days. We demonstrated that PTB7 blends using fullerene derivative $\mathrm{PC}_{70} \mathrm{BM}$ form stable $\mathrm{BHJs}$ in which fullerene diffusion is not observed up to temperature of $140{ }^{\circ} \mathrm{C}$. This can be addressed to local minima in the mixing enthalpy of the blend that corresponds to densely packed PTB7:PC ${ }_{70} \mathrm{BM}$ aggregates inside the mixed phases of the blends inhibiting fullerene diffusion between polymer- and fullereneenriched phases. By applying these thermally stable blends to devices, we demonstrate that the presence of residual additive DIO inside the blend generates strong losses in device performance at moderate thermal stress. After removing DIO from the device with a high-temperature annealing step, PTB7:PC ${ }_{70} \mathrm{BM}$-based solar cells exhibit remarkably high temperature stability during permanent annealing at $140{ }^{\circ} \mathrm{C}$ for several days, which can be directly related to the intrinsically stability of the polymer blend. We believe that our findings on suppression of fullerene diffusion inside $\mathrm{BHJs}$ will open new approaches for material design to improve thermal stability of organic solar cells.

\section{Experimental Section}

$\mathrm{ZnO}$ Nanoparticle Solutions: $\mathrm{ZnO}$ nanoparticles were prepared as published elsewhere. ${ }^{[57,64]}$ Then solution of $\mathrm{ZnO}$ nanoparticles with $6 \mathrm{~nm}$ as average diameter were prepared by transferring the as synthesized $\mathrm{ZnO}$ nanoparticles from methanol to isopropanol (IPA) mixed with ethanolamine $\left(0.2\right.$ vol\%) (EA). ${ }^{[57]}$ By this technique, cluster-free $\mathrm{ZnO}$ nanosphere solution in IPA of concentration of $7.5 \mathrm{mg} \mathrm{mL}^{-1}$ was prepared.

Figure 5. a) Annular dark-field image of the lamellar cross-section of the nonannealed device and b) corresponding plasmon peak map using STEM-SI (Scale bars $50 \mathrm{~nm}$ ). c,d) Plasmon peak maps of cross-sections of devices annealed at $140{ }^{\circ} \mathrm{C}$ for c) $1 \mathrm{~h}$ and d) $24 \mathrm{~h}$ (Scale bars $25 \mathrm{~nm}$ ); the photoactive layer was processed with DIO. 
Solar Cells Fabrication and Characterization: Solar cells using normal device structures were processed as follow. First ITO substrates (purchased from Lumtec, $15 \mathrm{Ohm} \mathrm{sq}^{-1}$ ) were thoroughly cleaned by sonication in acetone and ethanol followed by rinsing with water and sonication in IPA and applying ultraviolet-ozone for $10 \mathrm{~min}$. A thin layer of poly(3,4-PEDOT:PSS) (CLEVIOSTM AI 4083) was spin-coated on the cleaned ITO precoated glass substrate at the speed of $4000 \mathrm{rpm}$ for $60 \mathrm{~s}$ followed by heating on a hot-plate at $140{ }^{\circ} \mathrm{C}$ for $15 \mathrm{~min}$. The substrates were then transferred to a nitrogen-filled glovebox. PTB7 (1-Materials) and $\mathrm{PC}_{70} \mathrm{BM}$ ( $99 \%$ and $95 \%$ purity purchased from Solenne and Nano-C, respectively) were mixed with a ratio of 1:1.5. The $P T B 7: \mathrm{PC}_{70} \mathrm{BM}$ active blend layer, with a nominal thickness of $90 \mathrm{~nm}$, was prepared by spincoating a mixed solvent of chlorobenzene/1,8-diiodoctane (97:3\% by volume) solution (concentration, $25 \mathrm{mg} \mathrm{mL}^{-1}$ of PTB7:PC ${ }_{70} \mathrm{BM}$ ) at 1800 r.p.m. for 2 min. After dried in vacuum overnight, different concentration of $\mathrm{ZnO}$ nanoparticles in IPA and $0.2 \%(\mathrm{v} / \mathrm{V})$ ethanol amine has been spin-coated on the top of active layers at $1500 \mathrm{rpm}$ for $1 \mathrm{~min}$ and dried at hot plate at $80{ }^{\circ} \mathrm{C}$ for $5 \mathrm{~min}$. In order to study the impact of $\mathrm{ZnO}$ layers in detail, we prepared sets of devices under identical conditions by only changing one parameter such as for example $\mathrm{ZnO}$ concentration in IPA. For processing the cathode, samples were put into a MBRAUN evaporator inside the glovebox, in which Al metal electrodes $(100 \mathrm{~nm})$ were thermally evaporated at $2 \times 10^{-6}$ Torr pressure through a shadow mask defining the device area to $0.27 \mathrm{~cm}^{2}$ (standard cells) and $1 \mathrm{~cm}^{2}$ (large area). The current density-voltage $(\mathrm{V}-\mathrm{V})$ characteristics of the devices were measured using a Keithley 238 Source Measure Unit inside the glovebox using Lumtec substrates. Solar cell performance was measured by using a Newport class AAA 1.5 Global solar simulator (Oriel Sol3ATM model $n^{\circ} 94043 A$ ) with an irradiation intensity of $100 \mathrm{~mW} \mathrm{~cm}{ }^{-2}$. The light intensity was determined with a Si reference cell (Newport Company, Oriel $n^{\circ} 94043 \mathrm{~A}$ ) calibrated by National Renewable Energy Laboratory (NREL). Spectral mismatch factors (M) were calculated according to a standard procedure ${ }^{[57]}$ and $M$ values of 1.02 was obtained for the PTB7:PC ${ }_{70} B M$ devices. The value was used to correct the measured $J_{\mathrm{sc}}$ values of the solar cells to $J_{\mathrm{sc}}$ values corresponding to AM1.5G conditions. Shadow masks were used to well define the illuminated area to $0.27 \times 1.0 \mathrm{~cm}^{2}$. Comparison of masked and unmasked solar cells gave consistent results with photocurrent increase by less $2 \%$ for unmasked devices. We present performance of the best devices, while average PCEs were obtained with standard deviation analysis calculated using nine devices. External quantum efficiency measurements were performed in air using a homemade setup consisting of a Keithley 238 Source Measure Unit and Newport monochromator. Light intensity was measured with a calibrated Si-diode from Newport Company.

Electronic Characterization of the ZnO Interfaces in Complete Solar Cells: Impedance spectroscopy measurements were performed using an Autolab PGSTAT-30 equipped with a frequency analyzer module. A small voltage perturbation $(20 \mathrm{mV} r \mathrm{rs})$ is applied at frequencies from $1 \mathrm{MHz}$ to $1 \mathrm{~Hz}$. Measurements were carried out under 1 sun light intensity calibrated with a monocrystalline silicon photodiode sweeping the DC voltage in the range 0 to $V_{\text {oc }}$. Recombination resistance $\left(R_{\text {rec }}\right)$ and chemical capacitance $\left(C_{\mu}\right)$ are directly extracted from the high-frequency region as previously reported ${ }^{[57]}$ and the contact resistance under low frequencies.

Morphological Analysis of Blend Layers: Optical microscope analyses were performed with a confocal laser scanning microscope (LSM710 Zeiss). Polymer blends were deposited by spin coating on glass substrates with identical deposition parameters us used in solar cells and exposed to different annealing temperatures in air. For lateral, morphological analysis, photoactive layers prepared on PEDOT:PSS were floated on top of a deionized water surface followed by collection of pieces using a standard electron microscopy sample grid covered with a holey carbon film (QUANTIFOIL). Dark-field and spectroscopic measurements were performed using a Titan 60-300 microscope (FEI), equipped with an Enfinium (Gatan) spectrometer, and operated at an acceleration voltage of $120 \mathrm{kV}$ in scanning transmission mode. This allows acquisition of a low-energy-loss spectrum for each scan position with high energy-resolution and including the zero-loss peak information for computing single-scattering distributions by Fourier-log deconvolution. Before recording spectral imaging data sets, the scanned areas were exposed to a constant, small electron dose to avoid varying amounts of initial damage for different samples, which could influence the electronic structure of the organic semiconductors and thus the optical excitation signals. This ensures that material contrast based on plasmon maps is insensitive to varying damage induced signals. For spectral data sets the step size for the scanning was set to $3 \mathrm{~nm}$ with a dwell time of $0.5 \mathrm{~ms}$. The resulting dose was 250 e per $\AA^{2}$. The convergence angle was set to $10 \mathrm{mrad}$ to increase the probe diameter and contrast in dark-field imaging. The collection angle was set to $40 \mathrm{mrad}$. Spectral imaging data sets were imported into HyperSpy (http://hyperspy.org), an open-source Python library for interactive data analysis of multidimensional data. With HyperSpy all following data treatment steps were realized. First, shifts between spectra were corrected followed by Fourier-log deconvolution using a custom script. Second, plasmon peaks were fitted by a Lorentzian function, in the interval of $12-32 \mathrm{eV}$. The resulting model parameters include one parameter for the peak center. This center positions were stored in a map and color coded to visualize compositional variations at the nanoscale. For segmentation of the multidimensional data sets, the deconvolved data were imported into ilastik, an interactive tool for image classification, segmentation, and analysis. ${ }^{[65]}$ Segmentation into three classes was done as described elsewhere ${ }^{[44]}$ applying a nonlinear technique for dimensionality reduction. Cross-sections were prepared using a Helios Nanolab 650 (FEI), a DualBeam system for ion-milling and high-resolution scanning electron microscopy. To record electron energy-loss spectra of iodine signal from the DIO (see Supporting Information), the same microscope and spectrometer were used.

Molecular Dynamics Methods: The PTB7 polymer, $\mathrm{PC}_{60} \mathrm{BM}$, and $\mathrm{PC}_{70} \mathrm{BM}$ fullerene derivatives have been modeled using the General Amber Force Field (GAFF) ${ }^{[66]}$ successfully applied to study organic ${ }^{[67]}$ as well as organic-inorganic systems. ${ }^{[68]}$ The atomic partial charges were calculated according to the standard AM1-BCC method [am1-bcc] and the dispersive (i.e., van der Waals) interactions (both intra-and intermolecular) were described by the sum of two-body Lennard-Jones contributions, with Amber force field parameters.

Model potential molecular dynamics simulations were performed by using the NAMD 2.0 molecular simulations package. ${ }^{[69]}$ The equations of motion of atoms were integrated by using the Velocity Verlet algorithm with a time step as small as $1.0 \mathrm{fs}$. Multiple time stepping was used, with short-range nonbonded interactions calculated every two time steps and full electrostatics evaluated every four time steps. All the electrostatic contributions were computed by the Particle Mesh Ewald (PME) sum method, ${ }^{[0]}$ with grid spacing of $1 \AA$. Temperature was controlled by Langevin thermostat with damping coefficient of $1 \mathrm{ps}^{-1}$.

Rigid bonds conditions were applied for the hydrogens and the atoms to which they are bonded. The VMD 1.9 molecular visualization program has been used to analyze the trajectories. ${ }^{[54]}$ The PTB7 bulk consists of 20 regioregular PTB7 chains of length $\approx 12$ nanometer and periodically replicated along the backbone to mimic an infinite chain. Equilibration at room temperature and pressure was obtained by annealing by the Langevin thermostat and barostat ${ }^{[7]}$ (constant pressure constant temperature NPT ensemble) with anisotropic cell fluctuations for 1 ns. The fullerene bulks were composed by 32 molecules and built accordingly to the conformation described in Casalegno et al. ${ }^{[72]}$ for both the species, and relaxed with the same procedure used for PTB7. The cohesive energy density (CED), has been calculated by subtracting at the energy of the relaxed systems those of the isolated molecules and dividing for the equilibrated volume.

\section{Supporting Information}

Supporting Information is available from the Wiley Online Library or from the author. 


\section{Acknowledgements}

The authors acknowledge financial support by the French Fond Unique Interministériel (FUI) under the project "SFUMATO" (grant number: F1110019V/201308815) as well as by the European Commission under the Project "SUNFLOWER" (FP7-ICT-2011-7, grant number: 287594). Generalitat Valenciana (ISIC/2012/008 Institute of Nanotechnologies for Clean Energies) is also acknowledged for providing financial support. The authors further acknowledge financial support via ERC Starting Grant Colouratoms (335078)

Received: July 8, 2016 Revised: September 9, 2016 Published online:

[1] J. You, L. Dou, K. Yoshimura, T. Kato, K. Ohya, T. Moriarty, K. Emery, C.-C. Chen, J. Gao, G. Li, Y. Yang, Nat. Commun. 2013, 4, 1446.

[2] W. Li, K. H. Hendriks, W. S. C. Roelofs, Y. Kim, M. M. Wienk, R. A. J. Janssen, Adv. Mater. 2013, 25, 3182.

[3] Y. Li, Acc. Chem. Res. 2012, 45, 723.

[4] N. Li, C. Brabec, Energy Environ. Sci. 2015, 8, 2902.

[5] S. B. Dkhil, M. Pfannmöller, S. Bals, T. Koganezawa, N. Yoshimoto, D. Hannani, M. Gaceur, C. Videlot-Ackermann, O. Margeat, J. Ackermann, Adv. Energy Mater. 2016, 6, 1600290.

[6] L. Zuo, S. Zhang, H. Li, H. Chen, Adv. Mater. 2015, 27, 6983.

[7] S. Hong, H. Kang, G. Kim, S. Lee, S. Kim, J.-H. Lee, J. Lee, M. Yi, J. Kim, H. Back, J.-R. Kim, K. Lee, Nat. Commun. 2016, 7, 10279.

[8] M. Jørgensen, K. Norrman, S.-A. Gevorgyan, T. Tromholt, B. Andreasen, F. C. Krebs, Adv. Mater. 2012, 24, 580.

[9] N. Grossiord, J. M. Kroon, R. Andriessen, P. W. M. Blom, Org. Electron. 2012, 13, 432.

[10] P. Cheng, X. Zhan, Chem. Soc. Rev. 2016, 45, 2544.

[11] S. A. Gevorgyan, M. V. Madsen, B. Roth, M. Corazza, M. Hösel, R. R. Søndergaard, M. Jørgensen, F. C. Krebs, Adv. Energy Mater. 2016, 6, 1501208

[12] R. Roesch, T. Faber, E. von Hauff, T. M. Brown, M. Lira-Cantu, H. Hoppe, Adv. Energy Mater. 2015, 5, 1501407.

[13] X. Yang, J. Loos, S. C. Veenstra, W. H. J. Verhees, M. M. Wienk J. M. Kroon, M. A. J. Michels, R. A. J. Janssen, Nano Lett. 2005, 5, 579.

[14] S. Bertho, G. Janssen, T. J. Cleij, B. Conings, W. Moons, A. Gadisa, J. D'Haen, E. Goovaerts, L. Lutsen, J. Manca, D. Vanderzande, Sol. Energy Mater. Sol. Cells 2008, 92, 753.

[15] K. Sivula, Z. T. Ball, N. Watanabe, J. M. J. Fréchet, Adv. Mater. 2006, 18, 206.

[16] C. Renaud, S. J. Mougnier, E. Pavlopoulou, C. Brochon, G. Fleury, D. Deribew, G. Portale, E. Cloutet, S. Chambon, L. Vignau, G. Hadziioannou, Adv. Mater. 2012, 24, 2196.

[17] R. C. Mulherin, S. Jung, S. Huettner, K. Johnson, P. Kohn, M. Sommer, S. Allard, U. Scherf, N. C. Grennham, Nano Lett. 2011, 11, 4846.

[18] Y. Zhang, H. Yip, O. Acton, S. K. Hau, F. Huang, A. K. Y. Jen, Chem. Mater. 2009, 21, 2598.

[19] X. Meng, W. Zhang, Z. Tan, Y. Li, Y. Ma, T. Wang, L. Jiang, C. Shu, C. Wang, Adv. Funct. Mater. 2012, 22, 2187.

[20] Y. Lin, J. A. Lim, Q. Wie, S. C. B. Mannsfeld, A. L. Briseno, J. J. Watkins, Chem. Mater. 2012, 24, 622.

[21] M.-H. Liao, C.-E. Tsai, Y.-Y. Lai, F.-Y. Cao, J.-S. Wu, C.-L. Wan, C.-S. Hsu, I. Liau, Y.-J. Cheng, Adv. Funct. Mater. 2014, 24, 1418.

[22] S. Bertho, B. Campo, F. Piersimoni, D. Spoltore, J. D'Haen, L. Lutsen, W. Maes, D. Vanderzande, J. Manca, Sol. Energy Mater. Sol. Cells 2013, 110, 69

[23] S. A. Gevorgyan, F. C. Krebs, Chem. Mater. 2008, 20, 4386.

\section{www.MaterialsViews.com}

[24] Z. Li, H. C. Wong, Z. Huang, H. Zhong, C. H. Tan, W. C. Tsoi, J. S. Kim, J. R. Durrant, J. T. Cabral, Nat. Commun. 2013, 4, 2227.

[25] H. C. Wong, Z. Li, C. H. Tan, H. Zhong, Z. Huang, H. Bronstein, I. McCulloch, J. T. Cabral, J. R. Durrant, ACS Nano 2014, 2, 1297.

[26] G. Wantz, L. Derue, O. Dautel, A. Rivaton, P. Hudhommed, C. Dagron-Lartigaue, Polym. Int. 2014, 63, 1346.

[27] L. Derue, O. Dautel, A. Tournebize, M. Drees, H. Pan, S. Berthumeyrie, B. Pavageau, E. Cloutet, S. Chambon, L. Hirsch, A. Rivaton, P. Hudhomme, A. Facchetti, G. Wantz, Adv. Mater. 2014, 26, 5831 .

[28] C. Lindqvist, J. Bergqvist, O. Bäcke, S. Gustafsson, E. Wang, E. Olsson, O. Inganäs, M. R. Andersson, C. Müller, Appl. Phys. Lett. 2014, 104, 153301.

[29] C. Lindqvist, A. Sanz-Velasco, E. Wang, O. Backe, S. Gustafsson, E. Olsson, M. R. Andersson, C. Müller, J. Mater. Chem. A 2013, 1, 7174

[30] A. Diaz de Zerio Mendaza, J. Bergqvist, O. Bäcke, C. Lindqvist, R. Kroon, F. Gao, M. R. Andersson, E. Olsson, O. Inganäs, C. Müller, J. Mater. Chem. A 2014, 2, 14354.

[31] C. Lindqvist, J. Bergqvist, C.-C. Feng, S. Gustafsson, O. Bäcke, N. D. Treat, C. Bounioux, P. Henriksson, R. Kroon, E. Wang, A. Sanz-Velasco, P. M. Kristiansen, N. Stingelin, E. Olsson, O. Inganäs, M. R. Andersson, C. Müller, Ad. Energy Mater. 2014, 4, 1301437.

[32] J. J. Richards, A. H. Rice, R. D. Nelson, F. S. Kim, S. A. Jenekhe, C. K. Luscombe, D. C. Pozzo, Adv. Funct. Mater. 2013, 23, 514.

[33] F. Liu, W. Zhao, J. R. Tumbleston, C. Wang, Y. Gu, D. Wang, A. L. Briseno, H. Ade, T. P. Russell, Adv. Energy Mater. 2014, 4, 1301377.

[34] W. Chen, T. Xu, F. He, W. Wang, C. Wang, J. Strzalka, Y. Liu, J. Wen, D. J. Miller, J. Chen, K. Hong, L. Yu, S. B. Darling, Nano Lett. 2011, 11, 3707 .

[35] B. A. Collins, Z. Li, J. R. Tumbleston, E. Gann, C. R. Mcneill, H. Ade, Adv. Energy Mater. 2012, 3, 65.

[36] Z. He, C. Zhong, S. Su, M. Xu, H. Wu, Y. Cao, Nat. Photonics 2012 6, 591.

[37] M. Tessarolo, A. Guerrero, D. Gedefaw, M. Bolognesi, M. Prosa, X. Xu, M. Mansour, E. Wang, M. Seri, M. R. Andersson, M. Muccini, G. Garcia-Belmonte, Sol. Energy Mater. Sol. Cells 2015, 141, 240.

[38] K. Tada, Sol. Energy Mater. Sol. Cells 2015, 132, 15.

[39] C.-G. Wu, C.-H. Chiang, H.-C. Han, J. Mater. Chem. A 2014, 2, 5295.

[40] E.-P. Yao, Y.-J. Tsai, W.-C. Hsu, Int. J. Photoenergy 2014, 2014, 952528

[41] N. Li, C. J. Brabec, Energy Environ. Sci. 2015, 8, 2902.

[42] M. Pfannmöller, W. Kowalsky, R. R. Schröder, Energy Environ. Sci. 2013, 6, 2871.

[43] M. Pfannmöller, H. Heidari, L. Nanson, O. R. Lozman, M. Chrapa, T. Offermans, G. Nisato, S. Bals, Nano Lett. 2015, 15, 66346642.

[44] M. Pfannmöller, H. Flügge, G. Benner, I. Wacker, C. Sommer, M. Hanselmann, S. Schmale, H. Schmidt, F. A. Hamprecht, T. Rabe, W. Kowalsky, R. R. Schröder, Nano Lett. 2011, 11, 3099.

[45] C. Müller, Chem. Mater. 2015, 27, 2740.

[46] Y. Zhao, G. Yuan, P. Roche, M. Leclerc, Polymer 1995, 36, 2211

[47] G. J. Hedley, A. J. Ward, A. Alekseev, C. T. Howells, E. R. Martins, L. A. Serrano, G. Cooke, A. Ruseckas, I. D. W. Samuel, Nat. Commun. 2013, 4, 2867.

[48] K. Feng, X. Xu, Z. Li, Y. Li, K. Li, T. Yu, Q. Peng, Chem. Commun. 2015, 51, 6290.

[49] M. J. Richardson, N. G. Savill, Polymer 1975, 16, 753.

[50] D. Liu, R. Osuna Orozco, T. Wang, Phys. Rev. E 2013, 88, 022601.

[51] C. Melis, L. Colombo, A. Mattoni, J. Phys. Chem. C 2011, 115, 576.

[52] C. Caddeo, A. Mattoni, Macromolecules 2013, 46, 8003.

[53] M. Williams, N. G. Tummala, S. G. Aziz, C. Risko, J.-L. Brédas, J. Phys. Chem. Lett. 2014, 5, 3427. 
[54] S. Bellani, M. Porro, C. Caddeo, M. I. Saba, P. B. Miranda, A. Mattoni, G. Lanzani, M. R. Antognazza, J. Mater. Chem. B 2015, 3, 6429 .

[55] A. E. Saba, A. Mattoni, J. Phys. Chem. C 2014, 118, 4687.

[56] C. Melis, A. Mattoni, L. Colombo, J. Phys. Chem. C 2010, 114, 3401.

[57] S. B. Dkhil, D. Duché, M. Gaceur, A. K. Thakur, F. B. Aboura, L. Escoubas, J.-J. Simon, A. Guerrero, J. Bisquert, G. Garcia-Belmonte, Q. Bao, M. Fahlman, C. Videlot-Ackermann, O. Margeat, J. Ackermann, Adv. Energy Mater. 2014, 4, 1400805.

[58] M. Fukunaga, T.-Q. Li, P. van Gelderen, J. A. de Zwart, K. Shmueli, B. Yao, J. Lee, D. Maric, M. A. Aronova, G. Zhang, R. D. Leapman, J. F. Schenck, H. Merkle, J. H. Duyn, Proc. Natl. Acad. Sci. USA 2010, 107, 3834.

[59] R. Ortega, Nucl. Instrum. Methods Phys. Res., Sect. B 2005, 231, 218.

[60] A. Guerrero, L. F. Marchesi, P. P. Boix, S. Ruiz-Raga, T. Ripolles-Sanchis, G. Garcia-Belmonte, J. Bisquert, ACS Nano 2012, 6, 3453.

[61] A. Guerrero, S. Chambon, H. Lionel, G. Garcia-Belmonte, Adv. Funct. Mater. 2014, 24, 6234.

[62] A. Guerrero, B. Dörling, T. Ripolles-Sanchis, M. Aghamohammadi, E. Barrena, M. G. Campoy-Quiles, G. Garcia-Belmonte, ACS Nano 2013, 7, 4637.
[63] A. Guerrero, N. F. Montcada, J. Ajuria, I. Etxebarria, R. Pacios, G. Garcia-Belmonte, E. Palomares, J. Mater. Chem. A 2013, 1, 12345.

[64] G. Mattioli, S. B. Dkhil, M. L. Saba, G. Malloci, C. Melis, P. Alippi, F. Filippone, P. Giannozzi, A. K. Thakur, M. Gaceur, O. Margeat, A. K. Diallo, C. Videlot-Ackermann, J. Ackermann, A. A. Bonapasta, A. Mattoni, Adv. Energy Mater. 2014, 4, 1301694.

[65] C. Sommer, C. Strähle, U. Köthe, F. A. Hamprecht, in Proc. Eighth IEEE Int. Symp. Biomedical Imaging (ISBI) 2011, p. 230, IEEE, Chicago, Illinois, USA.

[66] J. Wang, R. M. Wolf, J. W. Caldwell, P. A. Kollman, D. A. Case, J. Comput. Chem. 2004, 25, 1157.

[67] C. Caddeo, D. Fazzi, M. Caironi, A. Mattoni, J. Phys. Chem. B 2014, 118, 12556.

[68] G. Mattioli, C. Melis, G. Malloci, F. Filippone, P. Alippi, P. Giannozzi, A. Mattoni, A. Amore Bonapasta, J. Phys. Chem. C 2012, 116, 15439.

[69] J. C. Phillips, R. Braun, W. Wang, J. Gumbart, E. Tajkhorshid, E. Villa, C. Chipot, R. D. Skeel, L. Kalé, K. Schulten, J. Comput. Chem. 2005, 26, 1781.

[70] T. Darden, D. York, L. Pedersen, J. Chem. Phys. 1993, 98, 10089.

[71] W. Humphrey, A. Dalke, K. Schulten, J. Mol. Graphics 1996, 14, 33.

[72] M. Casalegno, S. Zanardi, F. Frigerio, R. Po, C. Carbonera, G. Marra, T. Nicolini, G. Raos, S. V. Meille, Chem. Comm. 2013, 49, 4525. 